\title{
Sclerochronology: editorial
}

\author{
Wolfgang Oschmann
}

Published online: 23 December 2008

(C) Springer-Verlag 2008

During the past decade, the body of literature on sclerochronology (Buddemeier et al. 1974) has increased enormously. The most recent definition of this tonguetwisting term was formulated by the organization committee (William S. Arnold, Douglas S. Jones, Irvy R. Quitmyer, Bernd R. Schöne and Donna M. Surge) of the 1st International Sclerochronology Conference held at St. Petersburg, FL, USA, in July 2007. This definition is currently only published at the conference webpage at http://www.scleroconferences.de (last checked: 17 November 2008) and because this description is the most concise to date, it seems justified to cite it here:

Sclerochronology is the study of physical and chemical variations in the accretionary hard tissues of organisms, and the temporal context in which they formed. Sclerochronology focuses primarily upon growth patterns reflecting annual, monthly, fortnightly, tidal, daily, and sub-daily increments of time entrained by a host of environmental and astronomical pacemakers. Familiar examples include daily banding in reef coral skeletons or annual growth rings in mollusk shells. Sclerochronology is analogous to dendrochronology, the study of annual rings in trees, and equally seeks to deduce organismal life history traits as well as to reconstruct records of environmental and climatic change through space and time.

This special issue of International Journal of Earth Sciences aims to present an overview of the current research directions in the growing field of coral and bivalve

W. Oschmann $(\bowtie)$

Institute of Geosciences, University of Frankfurt, Altenhöferalle 1, 60438 Frankfurt am Main, Germany

e-mail: oschmann@em.uni-frankfurt.de mollusk sclerochronology. Most of the contributions in this compilation are selected papers from the session Assessing the Oceans' Role in Climate on Decadal to Centennial Timescales: A Paleo Perspective, which was held at the American Geophysical Union Ocean Sciences Meeting 2006 in Honolulu, Hawai'i convened by Miriam Pfeiffer, Jens Zinke and Bernd R. Schöne.

The reconstruction of past climates from corals and bivalves largely depends on a profound understanding of the reliability and fidelity of proxy records preserved in these accretionary biogenic hard parts. For example, individual differences in recording the ambient environment have often been neglected, and most previous reconstructions were based on single coral cores. However, Cahyarini et al. (this issue) and Pfeiffer et al. (this issue) show that $\mathrm{Sr} / \mathrm{Ca}$ ratios of contemporaneous corals may exhibit significant individual variability limiting quantitative estimates of sea surface temperature reconstructions. Both papers suggest the use to multi-specimen averages rather than relying on data from a single coral core. Such averaging of single core data from the Indian Ocean allowed SST reconstructions to the nearest $0.35^{\circ} \mathrm{C}$ or better (Pfeiffer et al., this issue). The sampling technique may also affect the results. According to Cahyarini et al. (this issue) horizontal sampling of corals should be preferred over vertical coring.

Corals from different localities preserve climate information in different ways. This is particularly true for oxygen isotope records of Indian Ocean corals (Zinke et al., this issue; Crueger et al., this issue). For example, large scale air temperature patterns in the Indian Ocean sector are fairly well represented by coral $\delta^{18} \mathrm{O}$ data, whereas teleconnections between coral oxygen isotopes and precipitation over different parts of Africa underlie significant interannual variability (Zinke et al., this issue). 
Likewise, Crueger et al. (this issue) point out that $\delta^{18} \mathrm{O}$ data from corals in different localities may preserve different aspects of the Pacific Decadal Oscillation (PDO). La Réunion corals record the sea surface temperature component of the PDO, whilst in Ifaty, the corals record the sea level pressure component.

Anthropogenic pollution may also affect the potential of biogenic skeletons to preserve climate signals. Typically, shell growth of the bivalve mollusk, Arctica islandica, in the Baltic and North Seas is strongly controlled by the North Atlantic Oscillation (NAO). However, in waters that were affected by heavy anthropogenic pollution related to mining and industrial development such as the Swedish West coast, the correlation between the NAO and annual shell growth has vanished (Dunca et al., this issue).

One hitherto completely ignored aspect of sclerochronology is the health state and survival rate of organisms. Soniat et al. (this issue) demonstrate that parasite infection and the mortality of oysters is governed by climate oscillations such as ENSO (El Niño-Southern Oscillation) and the NAO and associated changes in temperature and salinity. In addition, parasite proliferation, i.e. the response of an organism to climate variation may differ among different localities. Such findings may stimulate future sclerochronological studies. For example, changes in population density are well known to affect growth rates and therefore the potential of surviving bivalves to capture environmental changes. Moreover, sick bivalves may not reliably record environmental changes as well.

Aside from calibration and evaluation studies this special issue also reports new applications of bivalve sclerochronology at reconstructing past environmental variability. Wanamaker et al. (this issue) used shells of A. islandica from the northwest Atlantic to reconstruct paleo-productivity changes during the Medieval Warm
Period. According to their findings, the NAO exerts a major influence on zooplankton abundance and therefore on shell growth. Another bivalve shell-based (A. islandica) study is by Schöne and Fiebig (this issue) in which today's seasonal and average water temperatures in the North Sea are compared to that during the Deglacial and the Late Medieval Warmth. Results suggest that seasonal variability during the Allerød was as large as today, but that the winter-summer difference was strongly reduced during the Medieval times.

Climate proxies derived from biogenic hardparts can be used to test and verify climate models. This is important because the validity of statistical climate reconstructions is sometimes questionable. In the last paper of this special issue, von Storch et al. (this issue) used the model ECHO-G to reconstruct annual temperatures of the Northern Hemisphere during the last millennium with three different methods. Their major finding is that network size is the most relevant factor for determining the robustness of the climate model.

I would like to thank all contributors to this special issue for their efforts and patience and the numerous referees for their help in improving the quality of the manuscripts. Particular thanks go to the Editor-in-chief, Wolf-Christian Dullo and the Springer team for the opportunity to publish this special issue on sclerochronology in the International Journal of Earth Sciences.

\section{References}

Buddemeier RW, Maragos JE, Knutson DW (1974) Radiographic studies of reef coral exoskeletons: rates and patterns of coral growth. J Exp Mar Biol Ecol 14:179-200 